\title{
Electrochemical Activity and Electrical Properties of Optimized Polypyrrole Coatings on Iron
}

\author{
Karolina Cysewska, ${ }^{a}$ Sannakaisa Virtanen, ${ }^{\mathbf{b}, *}$ and Piotr Jasiński ${ }^{\mathrm{a}, *, \mathbf{z}}$ \\ ${ }^{a}$ Faculty of Electronics, Telecommunications and Informatics, Gdansk University of Technology, \\ 80-233 Gdansk, Poland \\ ${ }^{b}$ Department of Materials Science, WW4 -LKO, University of Erlangen-Nuremberg, 91058 Erlangen, Germany
}

\begin{abstract}
In this work, electrochemical activity and electrical properties of polypyrrole (PPy) coated iron electrodes have been investigated. PPy film was electrochemically polymerized from sodium salicylate aqueous solution under conditions, which provided an increase of iron corrosion resistance. It was noticed that the $\mathrm{pH}$ of the solution and the applied electrode potential range during the study of the polymer properties had an influence on the observed electroactivity of PPy. The electroactivity of PPy was retained in neutral solution when the potential was scanned between -0.6 and $0.3 \mathrm{~V}$. Also the resistance behavior of the synthesized polymer film as a function of the electrode potential during doping/dedoping processes was studied. Determination of the resistance was based on the impedance spectroscopy measurements and was performed in air, in order to avoid the influence of the solution resistance on the resistance of the studied polymer. Depending on the redox properties, the $\mathrm{pH}$ of solution and the potential range, different resistances of the polymer film during the doping/dedoping process can be obtained.

(C) The Author(s) 2015. Published by ECS. This is an open access article distributed under the terms of the Creative Commons Attribution Non-Commercial No Derivatives 4.0 License (CC BY-NC-ND, http://creativecommons.org/licenses/by-nc-nd/4.0/), which permits non-commercial reuse, distribution, and reproduction in any medium, provided the original work is not changed in any way and is properly cited. For permission for commercial reuse, please email: oa@electrochem.org. [DOI: 10.1149/2.0821512jes] All rights reserved.
\end{abstract}

Manuscript submitted July 27, 2015; revised manuscript received September 11, 2015. Published September 19, 2015.

In recent years, there is increasing interest to create a biodegradable, metallic, cardiovascular stent as an alternative for its permanent form. ${ }^{1,2}$ Iron and its alloys are promising materials for this application and have attracted attention of many researchers. ${ }^{2,3-6}$ Iron shows a good mechanical behavior, possesses favorable biological properties and a good biocompatibility. However, the degradation rate and the biological performance need to be controlled and optimized. ${ }^{1,2}$ One possible way to optimize the performance, is coating the metal with conducting polymers. ${ }^{5,7}$ To support non-toxicity of such an implant, drug molecules can be incorporated in the polymer film, which could be released from the polymer during the implant degradation, and hence possible inflammation reactions would be decreased.

One of the most interesting candidates among conducting polymers is polypyrrole (PPy).$^{8-10}$ Because of its high biocompatibility, ${ }^{11}$ good environmental stability, ${ }^{8}$ higher conductivity compared to many other conducting polymers, ${ }^{8}$ PPy can be used in various applications including anti-corrosive coatings ${ }^{7}$ and controlled drug release systems. ${ }^{12}$ PPy like other conducting polymers exhibits redox switching ability between its reduced and oxidized states. ${ }^{13}$ During the synthesis, a positively charged PPy backbone is formed and the polymer becomes oxidized. This is accompanied by the incorporation of the counter-anions into the polymer structure in order to achieve charge neutrality. ${ }^{14-16}$ After the synthesis, the polymer can be re-oxidized (doped) or reduced (dedoped) in order to change some of its properties. However, depending on the doping/dedoping electrolyte, charge neutrality will be maintained by the movement of anions, cations, or both into and out of the polymer film. ${ }^{15}$ Polypyrrole behavior depends strongly on its oxidation state. Reduced PPy films behave as electronic insulators, however oxidation of the polymer backbone generates charge carriers, which confer electronic conductivity to the polymer. ${ }^{17}$ Thus, to fully utilize the potential of its conductive and electroactive properties, it is necessary to study its different properties and behavior during these processes.

Polypyrrole can be electrosynthesized under different conditions on different metallic substrates from various types of solutions. ${ }^{18-23}$ Depending on the type of the doping agents, chemical, physical and electrical properties including electroactivity and redox capability of electrodeposited PPy film can be altered. ${ }^{11}$ Many investigations have been performed in order to evaluate the redox capability based on

*Electrochemical Society Active Member.

${ }^{\mathrm{z}}$ E-mail: pijas@eti.pg.gda.pl cyclic voltammetry measurements of polypyrrole synthesized in a presence of different electrolytes. ${ }^{15,17,20,24,25}$ Liu and Hwang ${ }^{20}$ investigated and proved the redox behavior of PPy film in $0.2 \mathrm{M}$ aqueous $\mathrm{KNO}_{3}$ solution by sweeping the potential between $-0.9 \mathrm{~V}$ and $0.4 \mathrm{~V}\left(10 \mathrm{mV} \cdot \mathrm{s}^{-1}\right)$. Based on cyclic voltammetry and Raman spectroscopy they observed that PPy films become roughened and smooth with oxidation and reduction, respectively. In another report, ${ }^{24} \mathrm{PPy}$ synthesized in a presence of electroactive ions in aqueous solution of $\mathrm{LiClO}_{4}$ was studied by cycling the potential between $0.5 \mathrm{~V}$ and $-0.8 \mathrm{~V}$. It was noted that oxidation/reduction peaks of these ions dominated over the corresponding peaks of PPy and did not diminish in subsequent scans. Based on this observation, it was noted that no ion-exchange took place for these conditions. ${ }^{24}$ Early redox (oxidation peak: $-0.3 \mathrm{~V}$, reduction peak: $-0.5 \mathrm{~V}$ ) process was observed for PPy coated on copper synthesized from sodium salicylate aqueous solution. This is expected for systems where immobilization or slow diffusity of anions in the polymer matrix takes place, the cations being also responsible for charge compensation. Also the peak current values were much higher for PPy grown from salicylate media (as compared to nitrate solution), which reinforces the role of polymer morphology on the extent of ion exchange. ${ }^{25}$ Electroactivity was also proved for PPy doped during its synthesis with polystyrenesulfonate/dodecylbenzenesulfonate (PPy/PSS/DBS), polyvinylphosphate/dodecylbenzenesulfonate (PPy/PVP/DBS $)^{15}$ and with chelating agents. ${ }^{14}$ Its electrochemical response was markedly dependent on the nature of the cation in the surrounding solution. ${ }^{14-15}$ However, the redox behavior of polypyrrole/potassium nitrate $\left(\mathrm{PPy} / \mathrm{KNO}_{3}\right)$ was noted to depend on the type of the anions present in the solution used for the investigation. ${ }^{17}$

It has also been reported that PPy films can be overoxidized when subjected to positive potentials for a long time, or higher potentials for a shorter times. Overoxidation of the polymer leads to irreversible loss of its electroactivity, ${ }^{26,27,28}$ as oxidation at positive potentials interrupts conjugation by formation of hydroxyl and carbonyl species. $^{29}$

Except for checking the electrochemical behavior of a polymer film, it is also important to characterize the behavior of a bare electrode substrate. Electrochemical behavior of Fe in various kinds of solutions such as malic acid, ${ }^{22}$ sodium tartrate, ${ }^{30}$ sodium salicylate, ${ }^{31}$ or sodium saccharinate ${ }^{32,26}$ has been investigated by many groups. Besides iron, also other metals such as platinum, ${ }^{22,31}$ zinc and aluminum, ${ }^{31}$ have been studied. For example, Petitjean et al. ${ }^{31}$ examined the electrochemical behavior of iron, zinc and platinum in sodium salicylate 
aqueous solution based on cyclic voltammetry measurements $(-1 \mathrm{~V}-$ $2.3 \mathrm{~V}$ ). Voltammograms for a zinc substrate in $1 \mathrm{M}$ sodium salicylate solution revealed three oxidation peaks at $-0.9 \mathrm{~V},-0.65 \mathrm{~V}$ and $+1 \mathrm{~V}$. The first two peaks corresponded to dissolution of the zinc substrate and precipitation of the metallic cation with salicylate molecules. However, the peak at $1 \mathrm{~V}$ involved salicylate oxidation. Electroactivity of an electrode can be also determined using chronopotentiometric methods. ${ }^{26}$ Based on this method, Bazzaoui et al. ${ }^{26}$ successfully investigated the behavior of iron in sodium saccharinate aqueous solution. Generally two processes were noticed after immersion of Fe in $0.1 \mathrm{M}$ sodium saccharinate aqueous solution and applying current density of $0.5,1,3$ and $5 \mathrm{~mA} \mathrm{~cm}{ }^{-2}$. The first one corresponded to dissolution of iron and to its passivation, and the second one was related to its transpassivity. It was also noted that the higher the applied current density was, the lower was the passivation stage.

Electroactivity, resistance behavior and thus the oxidation/reduction properties of polymeric films can differ depending on the studied type of the polymer, synthesization conditions, doping/dedoping solutions and scanning potential range. ${ }^{33,34}$ Several groups have reported on the resistance behavior of $\mathrm{PPy},{ }^{13}$ poly $(3$, 4-ethylenedioxythiophene) (PEDOT) ${ }^{35}$ and polyaniline (PANI) in different solutions as a function of the electrode potential during their doping/dedoping processes. Study of the redox and electrical properties of the polymer coatings could give information about a potential range, in which the polymer is electrochemically active and whether it exhibits insulating or conductive properties. Knowledge about this could help to control the degradation of metallic cardiovascular stents and drug release process from polymeric films coated on such implants. It could also be helpful in other biomedical applications, such as a conducting polymer-metallic electrode for neural stimulation. ${ }^{36,37}$ In this case, if there is a need to release drugs from a polymeric film, it will be necessary to obtain coatings with retaining electroactivity allowing continuous drug release. ${ }^{12}$

In this work, the electrochemical activity of PPy coated Fe electrodes in sodium salicylate aqueous solution was determined by cyclic voltammetry measurements. The PPy films were electrochemically polymerized from sodium salicylate aqueous solution under conditions, which were previously optimized to provide an increased corrosion resistance of iron. ${ }^{38}$ The salicylate molecules incorporated in the PPy layer during the coating process could act as a drug, which can be released into the body in biomedical applications, such as a cardiovascular biodegradable stent coated with a PPy film.

In this study, the relation between the resistance and the electrode potential applied during the doping/dedoping processes of optimized PPy coatings electropolymerized from sodium salicylate aqueous solution on Fe substrate was investigated for the first time. The polymer film was re-oxidized (doped) or reduced (dedoped) during the linear sweep voltammetry in the sodium salicylate aqueous solution. The resistance of the modified PPy film was measured in air, in order to avoid the influence of the solution resistance on the results. ${ }^{13}$ To the best of our knowledge, this approach has not been investigated before.

\section{Experimental}

Polymer films were electrochemically synthesized on iron $(\geq$ 99.5\%) (Chempur Feinchemikalien und Forschungsbedarf $\mathrm{GmbH}$ ) in a one step process from aqueous solution of pyrrole monomer $(\geq 98 \%)$ and sodium salicylate (EMSURE). The $\mathrm{pH}$ of solutions was adjusted with sodium hydroxide (POCH) or formic acid (Fisher Scientific UK).

Different setup configurations were used depending on the type of measurement. The coating and cyclic voltammetry measurements were performed in a one-compartment cell with three electrode system controlled by potentiostat VersaSTAT 4 . The working electrode for these measurements was an iron sheet $(18 \mathrm{~mm} \times 20 \mathrm{~mm})$ surrounded by epoxy resin with lead attached at the one side of the electrode with exposed area of $36 \mathrm{~mm}^{2}$. An $\mathrm{Ag} / \mathrm{AgCl}$ electrode in $3 \mathrm{M} \mathrm{KCl}$ solution was used as reference electrode and a platinum sheet $(10 \mathrm{~mm} \times$ $10 \mathrm{~mm}$ ) as counter electrode. Impedance spectroscopy (IS) measurements were carried out in a 2-electrode system controlled by Gamry
Instrument - Interface 1000. A working electrode (Fe double-band) for this measurement was prepared based on description provided by Kankare and Kupila. ${ }^{39}$ Here, the electrode consists of two separated iron sheets (each with dimension of $18 \mathrm{~mm} \times 1.5 \mathrm{~mm}$ ) with a gap between the sheets of $80 \mu \mathrm{m}$. This whole setup is surrounded by epoxy resin with leads attached to each sheet. The construction of a doubleband electrode allows for resistance measurements of a polymer film deposited between the iron sheets. In the early stages of electropolymerization, a polymer film is deposited onto the Fe sheets in both longitudinal and transverse directions. After some time of deposition, the polymer layer becomes thicker which results in connection of polymer film synthesized at each of Fe sheets. ${ }^{38}$ This connection can be seen in impedance spectrum as a sudden drop of impedance modulus, which begins to reflect the resistive behavior of the studied polymer.

The construction of working electrodes allowed obtaining reproducible electrode surface after grinding and polishing processes. The iron electrodes were mechanically polished with abrasive papers: 220 , 500, $1200 \mathrm{SiC}$ grade, respectively, rinsed with ethanol and dried. After the experiments, the samples were rinsed with distilled water and dried (for approximately 5 minutes in a warm air stream).

Electrochemical polymerization was performed galvanostatically at current density of $2.5 \mathrm{~mA} \cdot \mathrm{cm}^{-2}$ in aqueous solution of $0.1 \mathrm{M}$ sodium salicylate $(\mathrm{pH}$ ) and $0.1 \mathrm{M}$ pyrrole for 20 minutes $(\mathrm{Q}=4.72$ $\mathrm{C} \cdot \mathrm{cm}^{-2}$ ). This polymerization condition is the optimum condition of PPy synthesis providing a good increase of corrosion resistance of iron, as demonstrated in our earlier study on the complex optimization procedure of the PPy polymerization process on $\mathrm{Fe}^{38}$

Cyclic voltammograms were recorded in a monomer free aqueous solution of $0.1 \mathrm{M}$ sodium salicylate $(\mathrm{pH} 4,7,9)$ at different potential ranges vs. $\mathrm{Ag} / \mathrm{AgCl}$ reference electrode with a scan rate of $10 \mathrm{mV} \cdot \mathrm{s}^{-1}$. Selected ranges of potentials during the $\mathrm{CV}$ measurements $(-1.2$ to $1.2 \mathrm{~V}, 1.2 \mathrm{~V}$ to $-1.2 \mathrm{~V}$ and $-0.6 \mathrm{~V}$ to $0.3 \mathrm{~V}$ ) allowed observing different redox behaviors of PPy coated Fe electrode. The $\mathrm{pH}$ of conducted solutions was adjusted by sodium hydroxide or formic acid. Each experiment has been performed three times and the averages of these are presented.

In order to determine the relation between the resistance of PPy film and the electrode potential, the polymer film was gradually reoxidized (doped) and reduced (dedoped) during linear sweep voltammetry (from $-1.2 \mathrm{~V}$ to $1.2 \mathrm{~V}$ or from $-0.6 \mathrm{~V}$ to $0.3 \mathrm{~V}$ ) in $0.1 \mathrm{M}$ sodium salicylate aqueous solution with the scan rate of $10 \mathrm{mV} \cdot \mathrm{s}^{-1}$. Because the resistance of polymer is not only a sensitive function of the electrochemical potential but also of the chemical environment (such as the $\mathrm{pH}$ of the electrolyte), ${ }^{40} \mathrm{PPy}$ was doped and dedoped in sodium salicylate aqueous solution with different $\mathrm{pH}$ values. Impedance measurements were performed in order to determine the resistance of a PPy film during its doping and dedoping processes. The impedance measurements were performed at a frequency of $10 \mathrm{~Hz}$ against the open circuit potential and with an amplitude of $20 \mathrm{mV}$. The selected frequency provided the opportunity to determine the polymer film resistance from the impedance (it is the impedance value for which the phase angle is $0^{\circ}$ ). Because the resistance measured in-situ is the combination of polymer resistance and that of the supporting electrolyte and the double layer capacitance, ${ }^{13}$ here the impedance measurements were conducted in air, alternately with the doping/dedoping processes. First of all, the synthesized PPy film was doped/dedoped gradually during the linear sweep voltammetry in aqueous solution of sodium salicylate, then the sample was dried for approximately 5 minutes in warm air stream, subsequently the impedance measurement was performed in air.

Adhesion measurements were based on the standard sellotape test - ASTM Test Method D 3359 (ISO 2409).

\section{Results and Discussion}

Electrochemical activity of $\mathrm{Fe}$ in $0.1 \mathrm{M}$ sodium salicylate aqueous solution ( $\mathrm{pH} \mathrm{4,} \mathrm{7,9).-} \mathrm{Generally,} \mathrm{electroactivity} \mathrm{of} \mathrm{iron} \mathrm{in} 0.1$ M sodium salicylate aqueous solution (see Fig. 1) is characterized 

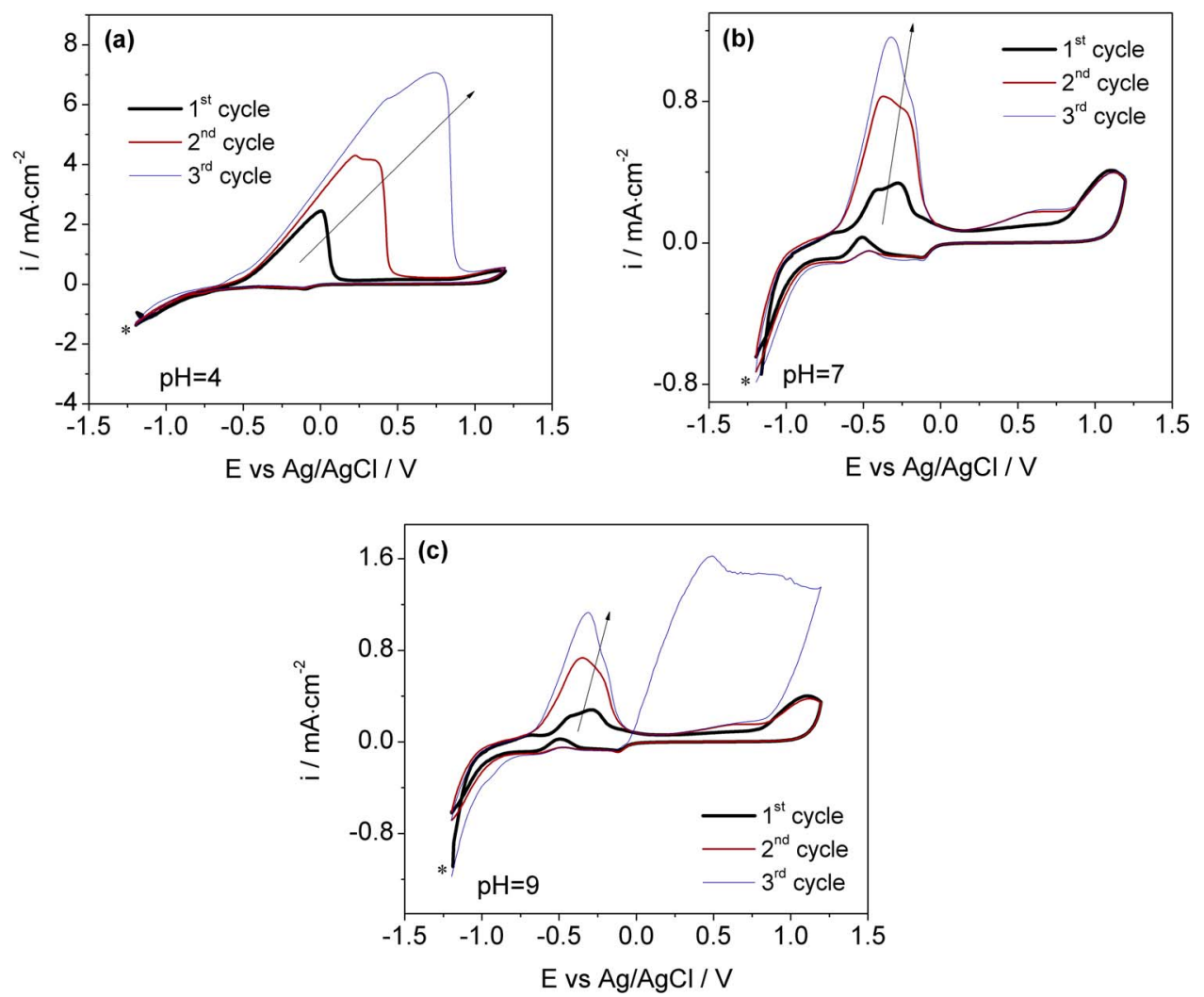

Figure 1. Cyclic voltammetry of bare Fe electrode in $0.1 \mathrm{M}$ sodium salicylate aqueous solution of pH (a) 4 , (b) 7 and (c) 9 . The star indicates the beginning of the measurement, while the arrows indicate direction of increasing number of scans.

by three specific regions: dissolution of iron, its passivation and the transpassive region. ${ }^{30}$ The first region corresponding to dissolution of $\mathrm{Fe}$ is seen in voltammograms as an increase of the current density. The second, a passivation stage, begins when the potential is scanned in a positive direction and the current density starts to decrease. In this region a passive layer is formed on the iron surface and it remains stable up to approximately $1 \mathrm{~V}$. At higher potentials, the transpassivation stage starts, where oxidation of water occurs resulting in destruction of the passive film. ${ }^{22,31}$ Similar behavior has been largely described in the case of malic acid, ${ }^{22}$ sodium tartrate ${ }^{30}$ and sodium saccharin ${ }^{32}$ aqueous solution. The described above general redox behavior of an $\mathrm{Fe}$ electrode can differ depending on the $\mathrm{pH}$ value of the solution in which the cyclic voltammetry is performed. Iron dissolution normally occurs at a potential of approximately $-0.44 \mathrm{~V}$, which is observed for the neutral (Figure 1b) and basic (Figure 1c) solution. Comparing the results with the Pourbaix diagram it can be noted that in a solution of $\mathrm{pH} 7$ and 9, formation of $\mathrm{Fe}$ (II) oxides/hydroxides, as well as $\mathrm{Fe}(\mathrm{III})$ oxides/hydroxides at higher potentials is expected, with a narrow region of stability of dissolved $\mathrm{Fe}^{2+} .{ }^{41}$ Based on the cyclic voltammetry measurements it can be also seen that dissolution of $\mathrm{Fe}$ sets on in each next cycle approximately at the same potential, but exhibits higher current densities, indicating progressive loss of passivity during transpassivation stage, allowing the metal to dissolve again. ${ }^{31}$ The same behavior was observed for acidic solutions. Scanning electron microscopy and atomic force microscopy images (not presented here) showed that the increase in current experienced by the electrode for each new scan is associated with the roughening of the electrode surface. For the acidic solution, after the third cycle, the root mean squared surface roughness of iron increased from approximately 50 to $500 \mathrm{~nm}$. Cyclic voltammetry of Fe in sodium salicylate basic aqueous solution presents a peak in the third scan at around $0.5 \mathrm{~V}$ that is not observed in the rest of the voltammograms (see Fig. 1c). This peak corresponds to oxidation of salicylate molecules and has also been observed by other authors. ${ }^{31}$
For the acidic solution (Figure 1a), the potential at which dissolution of iron occurs is shifted in the positive direction. After each cycle the shift is larger, resulting in a decrease of the potential regime of stable passivity. Also, the current density for this case is much higher than in neutral or basic solutions.

Electrochemical activity of PPy coated Fe electrodes in $0.1 \mathrm{M}$ sodium salicylate aqueous solution ( $p H 4,7,9)$. - The redox behavior of polypyrrole coated iron electrodes was examined in monomer free electrolyte solution. Figure 2 presents the respective cyclic voltammograms of PPy obtained in $0.1 \mathrm{M}$ sodium salicylate aqueous solution with the $\mathrm{pH}$ of 7 (a), 9 (c) and 4 (e) by sweeping the potential between $-1.2 \mathrm{~V}$ and $1.2 \mathrm{~V}$. Bare Fe electrodes and modified with PPy exhibited very different voltammetric responses (compare Figs. 1 and 2). Because the behavior of PPy coated Fe electrodes in $0.1 \mathrm{M}$ sodium salicylate aqueous solution was virtually the same for both $\mathrm{pH} 7$ and 9, only the results from the $\mathrm{pH} 7$ will be described in detail.

Three oxidation peaks $(-0.4 \mathrm{~V}, 0.1 \mathrm{~V}, 0.7 \mathrm{~V})$ were observed during the first cycle of PPy re-oxidation in a $\mathrm{pH}$ neutral solution when the potential was swept between $-1.2 \mathrm{~V}$ and $1.2 \mathrm{~V}$ (Fig. 2a). In subsequent cycles, the high anodic peak at about $+0.7 \mathrm{~V}$ disappeared. This is indicative of irreversibility of the overoxidation process. The irreversibility is confirmed by the absence of this anodic peak already in the 1 st cycle, when the potential sweep direction from -1.2 to $1.2 \mathrm{~V}$ was reversed, i.e. sweep from +1.2 to $-1.2 \mathrm{~V}$ (Fig. 2b). Irreversibility of overoxidation is consistent with data in the literature. ${ }^{28}$ Overoxidation does not proceed at potentials $+(0.3-0.4) \mathrm{V}$ (Fig. 2a), in agreement with results in refs.. ${ }^{25,28,42}$

Re-oxidation of PPy in acidic solution (Fig. 2e) reveals firstly one cathodic $(-1.1 \mathrm{~V})$ and secondly one anodic $(0.1 \mathrm{~V})$ peak. In the second scan, additionally one cathodic $(-0.9 \mathrm{~V})$ and one anodic $(-0.4 \mathrm{~V})$ peak showed up and disappeared in the following scans. It was also noticed that during the subsequent scans the current of anodic and cathodic peaks was decreasing, similar to the PPy studied in solution 

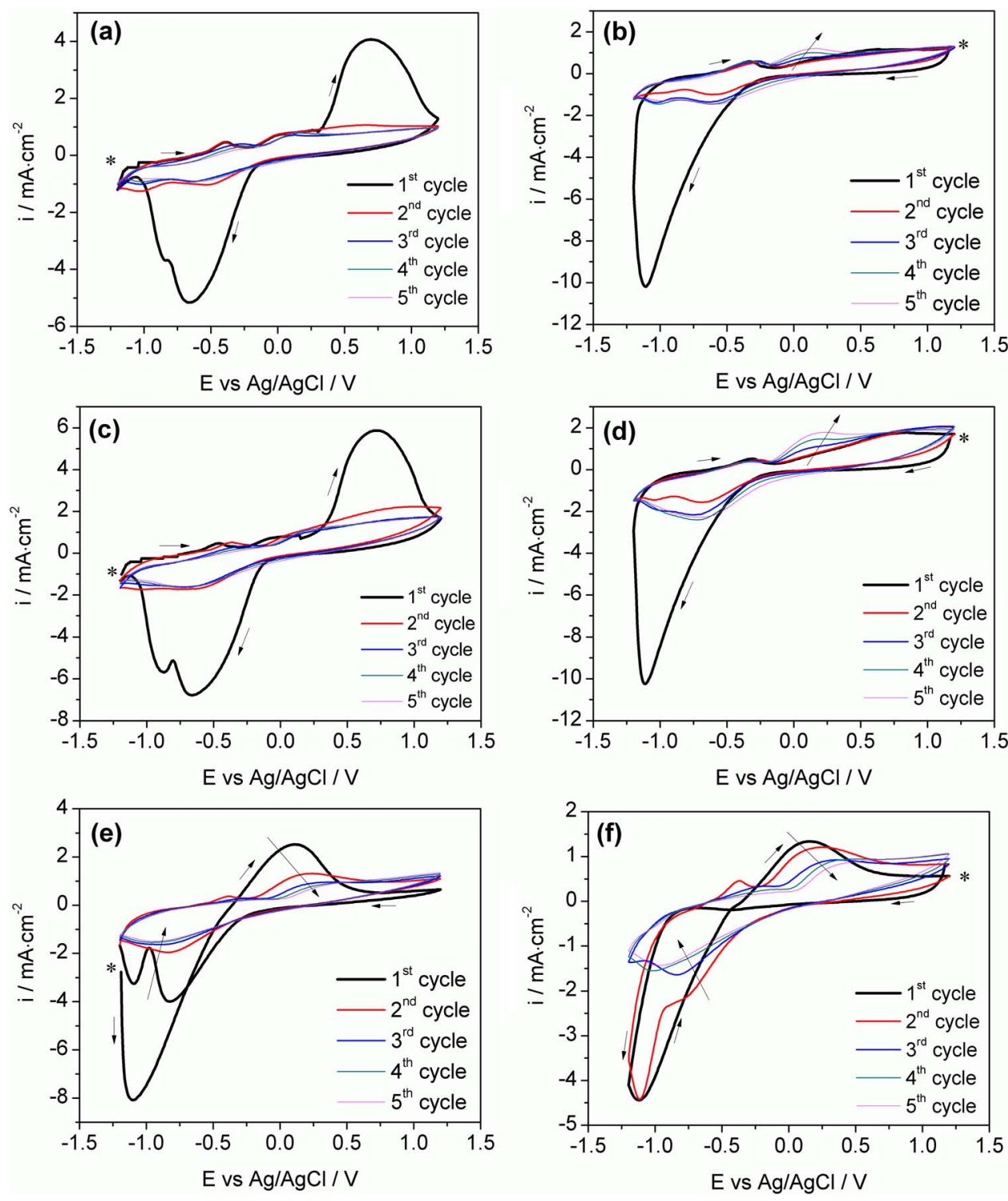

Figure 2. Cyclic voltammetry of PPy coated Fe electrodes in $0.1 \mathrm{M}$ sodium salicylate aqueous solution with the pH of 7 (a, b), 9 (c, d) and 4 (e, f) obtained by sweeping the potential between $-1.2-1.2 \mathrm{~V}(\mathrm{a}, \mathrm{c}, \mathrm{e})$ and between 1.2 and $-1.2 \mathrm{~V}(\mathrm{~b}, \mathrm{~d}, \mathrm{f})$ with the scan rate of $10 \mathrm{mV} \cdot \mathrm{s}^{-1}(5 \mathrm{cycles})$. The star indicates the beginning of the measurement, while the arrows indicate direction of increasing number of scans or direction of the first cycle.

of $\mathrm{pH}$ 7. Thus, the electroactivity of polymer in a solution of $\mathrm{pH} 4$ also decreases during the subsequent voltammetric cycles. Here, all of the occurring peaks are reversible, which indicates that probably there is no overoxidation of the polymer film. In order to confirm this, a cyclic voltammetry measurement of PPy was performed also by sweeping the potential between $1.2 \mathrm{~V}$ and $-1.2 \mathrm{~V}$ (Fig. 2f). In this measurement the redox behavior of the PPy coating was almost the same as in the case when the potential was swept starting from $-1.2 \mathrm{~V}$. Thus, no overoxidation process of studied polymer occurred, in agreement with the literature. ${ }^{28}$ It has been reported that the irreversible overoxidation occurs much more easily in an alkaline solution, due to nucleophilic attacks into the polymer backbone. It has also been observed that the higher the $\mathrm{pH}$ value of the solution, the lower the overoxidation potential of the polymer. ${ }^{28}$ Therefore, PPy measured in solution of $\mathrm{pH}$ 4 does not become overoxidized during re-oxidation as easily as in a neutral solution. However, the scanning potentials probably are still too high and lead to gradual decrease of the electroactivity of studied polymer.

In further studies, the potential range of PPy scanning was reduced. Figures $3 \mathrm{a}$ and $3 \mathrm{~b}$ present voltammograms of PPy coated $\mathrm{Fe}$ in
0.1 M sodium salicylate aqueous solution of $\mathrm{pH} 7$ and 4, respectively. In each case the potential was cyclically swept between $-0.6 \mathrm{~V}$ and $0.3 \mathrm{~V}$. This is a typical potential range for PPy studies in order to avoid its overoxidation. It can be seen that electroactivity of PPy in a neutral solution (Fig. 3a) was increasing during the subsequent voltammetric scans. Redox properties of PPy were retained after 80 cycles of potential. PPy in acidic solution exhibited some cathodic reactions at a potential of about $0.5 \mathrm{~V}$, however after the third cycle the polymer became totally inactive, which is also indicated by the presence of the low current density (in the range of some tens of $\mu \mathrm{A} / \mathrm{cm}^{2}$ ).

The adhesion of the PPy coatings was tested by applying ASTM sellotape test (standard ASTM D33359-09 norm). The PPy films after synthesis strongly adhered to the iron surface. No detachment of PPy coatings from the Fe surface after adhesion measurements is noticeable $(0-5 \%$ of removed area). The same was observed for the PPy coatings subjected to the potential range from $-0.6 \mathrm{~V}-$ $0.3 \mathrm{~V}$. Adhesion for PPy after its studies for five cycles under higher potentials $(-1.2-1.2 \mathrm{~V})$ was very poor. After 5 cycles of these measurements the polymer coating completely peeled off from the iron surface. 

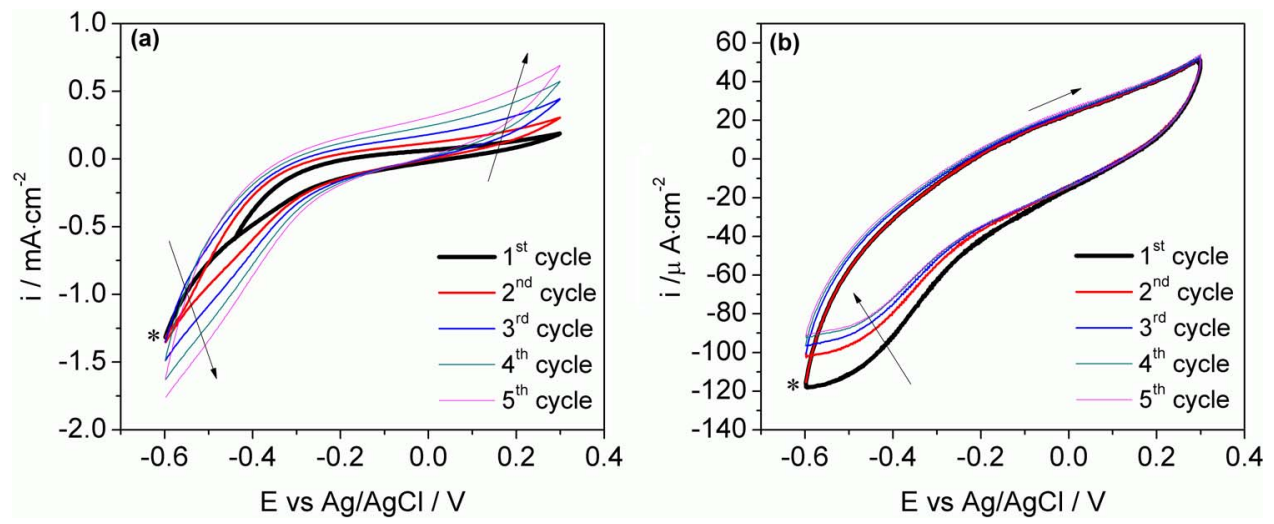

Figure 3. Cyclic voltammetry of PPy coated Fe electrodes in $0.1 \mathrm{M}$ sodium salicylate aqueous solution with the pH of 7 (a) and 4 (b) obtained by sweeping the potential between $-0.6 \mathrm{~V}$ and $0.3 \mathrm{~V}$ with the scan rate of $10 \mathrm{mV} \cdot \mathrm{s}^{-1}$ (5 cycles). The star indicates the beginning of the measurement, while the arrows indicate direction of increasing number of scans or direction of the first cycle.

The reason of differences in adherence between the coatings studied in aqueous solution of $0.1 \mathrm{M}$ sodium salicylate under different electrode potentials can be probably related with the overoxidation process, which can cause the loss of material due to formation of $\mathrm{CO}_{2} \cdot{ }^{29}$ The loss of the adhesion properties of the PPy can also occur when the system is subjected to potentials lower than $-0.5 \mathrm{~V}$ versus saturated calomel electrode (SCE) ${ }^{25}$

Resistance of PPy film as a function of electrode potential applied during doping/dedoping processes. - Figure 4 presents the resistance behavior of the PPy coated Fe electrode depending on the electrode potential applied during doping/dedoping processes. PPy was re-oxidized and reduced in a $0.1 \mathrm{M}$ sodium salicylate aqueous solution with the $\mathrm{pH}$ of 7 (a) and 4 (b) by gradually sweeping the potential from $-1.2 \mathrm{~V}$ to $1.2 \mathrm{~V}$ and back to $-1.2 \mathrm{~V}$ ( 1 cycle). In each case it can be noticed that the initial resistance of the synthesized PPy film is approximately $60 \mathrm{k} \Omega \pm 2 \mathrm{k} \Omega$, confirming the good reproducibility of the initial state of the polymer. The potential shift from $-1.2 \mathrm{~V}$ to $+0.8 \mathrm{~V}$ resulted in the resistance decrease to about 4 and $26 \mathrm{k} \Omega$ at $\mathrm{pH} 7$ and 4 , respectively. The further shift of the potential in the positive side to $+1.2 \mathrm{~V}$ and the consequent shift of potential in the negative side up to about $+(0.6-0.7) \mathrm{V}$ lead to some increase of resistance. The resistance reached the minimal values of about $5 \mathrm{k} \Omega$ at $-0.4 \mathrm{~V}$ and $20 \mathrm{k} \Omega$ at $-0.6 \mathrm{~V}$ for $\mathrm{pH} 7$ and 4 , respectively. The further shift of potential in the negative side resulted in a sharp increase of resistance to about $230 \mathrm{k} \Omega$ and in a slight increase of resistance to about 25 $\mathrm{k} \Omega$ for $\mathrm{pH} 7$ and 4 , respectively. The changes of the resistance of the polymer film during its re-oxidation or oxidation have been observed when the measurements were performed in a solution (in-situ). ${ }^{40,43}$

Different resistance behavior obtained in both cases (4a and 4b) can be related to different redox properties of synthesized PPy film, $\mathrm{pH}$ of doping solution, and type of anions present in this solution. The hysteresis occurring between the oxidation and reduction processes in both cases (Figs. 4a and 4b) can be due to the ion trapping into the polymer film. ${ }^{27}$ However, the significant increase of resistance (for potentials higher than $0.8 \mathrm{~V}$ ) which is observed for solution of $\mathrm{pH} 7$ can be related to overoxidation of the studied polymer film. This was not observed when the re-oxidation was performed in solution of $\mathrm{pH}$ 4. The poor adhesion of the PPy film to the surface of the iron allows, in this case, only measuring resistance during one re-oxidation and reduction cycle.

The resistance behavior was also measured when the doping and dedoping potentials were swept from $-0.6 \mathrm{~V}$ to $0.3 \mathrm{~V}$. Electroactivity is retained in the pointed potential range. Figure 5 presents the resistance of a PPy film as a function of the electrode potential measured in air. PPy was re-oxidized/oxidized and reduced in a $0.1 \mathrm{M}$ sodium salicylate aqueous solution with the $\mathrm{pH}$ of 7 by gradually sweeping the potential from $-0.6 \mathrm{~V}$ to $0.3 \mathrm{~V}$ and back to $-0.6 \mathrm{~V}$ ( 5 cycles) with the scan rate of $10 \mathrm{mV} \cdot \mathrm{s}^{-1}$.

It can be noticed that once the PPy was re-oxidizing (from $-0.6 \mathrm{~V}$ to $0.3 \mathrm{~V}$ ) its resistance was decreasing. However, during its reduction (from $0.3 \mathrm{~V}$ to $-0.6 \mathrm{~V}$ ) the resistance slightly decreases or became constant which can be related with the ions trapped in the polymer film. Nonetheless, the hysteresis between the oxidation and reduction processes is very small compared to the case when the applied
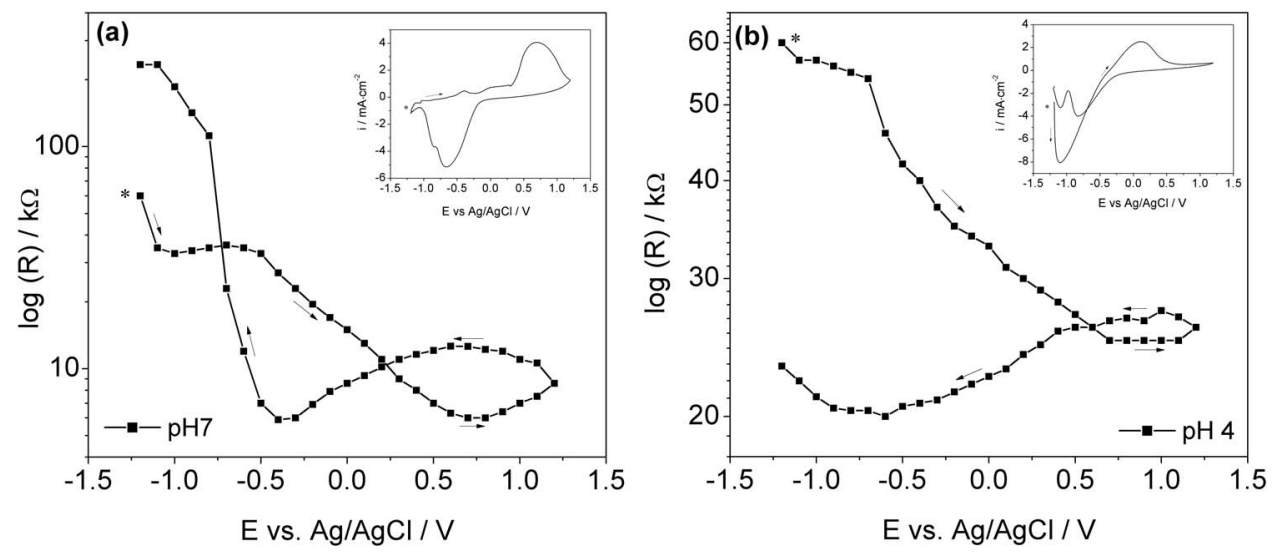

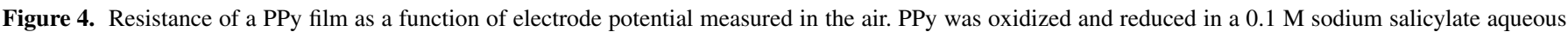

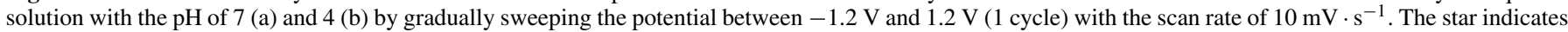
the beginning of the measurement, while the arrows indicate the direction of the scan. 


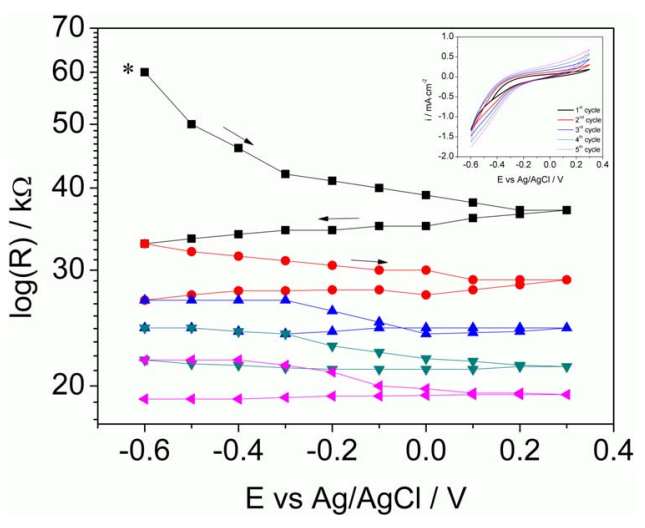

Figure 5. Resistance of a PPy film as a function of electrode potential measured in the air ( $1^{\text {st }}$ cycle $\mathbf{m}, 2^{\text {nd }}$ cycle $\bullet, 3^{\text {rd }}$ cycle $\Delta, 4^{\text {th }}$ cycle $\nabla, 5^{\text {th }}$ cycle $\varangle$ ). PPy was oxidized and reduced in a $0.1 \mathrm{M}$ sodium salicylate aqueous solution with the $\mathrm{pH}$ of 7 by gradually sweeping the potential between $-0.6 \mathrm{~V}$ and $0.3 \mathrm{~V}$ ( 5 cycle) with the scan rate of $10 \mathrm{mV} \cdot \mathrm{s}^{-1}$. The star indicates the beginning of the measurement, while the arrows indicate the direction of the scans.

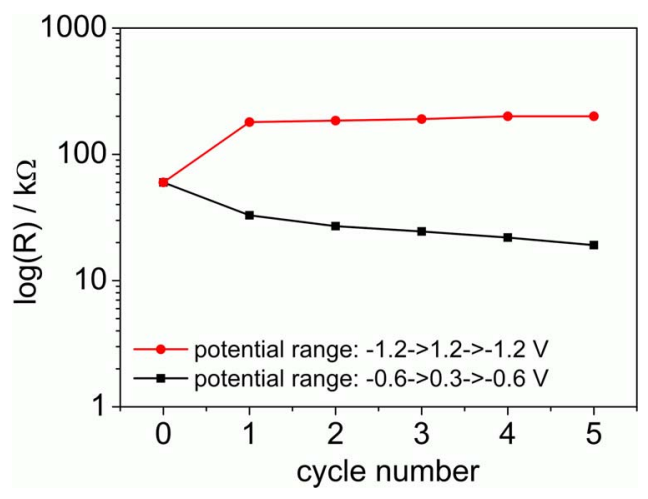

Figure 6. Resistance of PPy film coated Fe as a function of number of its doping and dedoping cycles with the potentials between $-1.2-1.2 \mathrm{~V}$ and $-0.6-0.3 \mathrm{~V}(\mathrm{pH} 7)$.

potentials range was of $1.2 \mathrm{~V}$ and $-1.2 \mathrm{~V}$, which allow for reversible doping and dedoping within one cycle.

Figure 6 presents the resistance of a PPy film as a function of number of doping/dedoping cycles with the potentials range between $-1.2-1.2 \mathrm{~V}$ and $-0.6-0.3 \mathrm{~V}$. When the PPy film was doped at potentials between $-0.6 \mathrm{~V}$ and $0.3 \mathrm{~V}$, its resistance decreased after each cycle; this behavior can be attributed to ion trapping. Different behavior was observed when PPy was subjected to potentials between $-1.2 \mathrm{~V}$ and $1.2 \mathrm{~V}$. In this case, the resistance after the first cycle increased from approximately $60 \mathrm{k} \Omega$ to the $220 \mathrm{k} \Omega$ and then remained almost constant during the following cycles. This kind of behavior can be another proof for the overoxidation of PPy occurring when the polymer is re-oxidized up to the $1.2 \mathrm{~V}$. Therefore, after the first cycle in which the overoxidation of the PPy film occurred, there is an increase in the resistance. However, during following doping and dedoping scans, no change of the resistance can be observed due to the loss of the electroactivity of the polymer.

\section{Conclusions}

The electrochemical activity and electrical properties of PPy coated on iron substrate were studied. PPy film was electrochemically polymerized from sodium salicylate aqueous solution under conditions, which have been previously optimized to provide an efficient corrosion protection of iron. Selected ranges of CV potentials allowed observing the different redox behaviors of the PPy coated Fe electrode. When the PPy was re-oxidized in a solution of $\mathrm{pH} 7$ and in a potential range between $-1.2 \mathrm{~V}$ and $1.2 \mathrm{~V}$, an irreversible anodic peak was observed that was related with the overoxidation of studied polymer. The electroactivity of PPy film was retained when the scanning potential range was applied between $-0.6 \mathrm{~V}$ and $0.3 \mathrm{~V}$ in a solution of $\mathrm{pH} 7$.

Poor adhesion was observed for the polymer coating on iron after scanning the potential between $-1.2 \mathrm{~V}$ and $1.2 \mathrm{~V}$ for five cycles in neutral solution. Polymer coating completely peeled off from the iron surface. No detachment of PPy coatings from Fe surface was noticeable when the polymer was scanned with the potentials between $-0.6 \mathrm{~V}$ and $0.3 \mathrm{~V}$.

Also electrical properties, such as the change of the polymer resistance depending on the electrode potential during doping/dedoping processes were investigated. The resistance measurement was performed in air in order to avoid the influence of the solution resistance on the resistance of the studied polymer film. Re-oxidation (doping) of the polymer resulted in decreasing of its resistance. When the potential exceeded $0.8 \mathrm{~V}$, the resistance of the polymer film started to increase which was related with the overoxidation of the studied polymer film. This was not observed for the PPy scanned with potentials between $-0.6 \mathrm{~V}$ and $0.3 \mathrm{~V}$. The resistance of a PPy film as a function of number of doping/dedoping cycles for different potential ranges was also determined and was different depending on the applied potential ranges.

By applying appropriate potentials to the synthesized polymer film, its redox and electrical properties can be tailored. The performed measurements in this work indicated the potential ranges in which the polymer can be used. It is challenging to achieve PPy coatings with retained electroactivity. However, this is crucial for a possible biomedical application. Based on the knowledge about the electroactivity and resistivity of the PPy-Fe electrode, future work about drug release from these coatings could be performed and controlled by changing the electrical properties of the electrochemically stable polymer film.

\section{Acknowledgment}

This work is partly supported by Statutory Funds for Research of Gdansk University of Technology.

\section{References}

1. M. Moravej and D. Mantovani, Int. J. Mol. Sci., 12, 4250 (2011).

2. Y. F. Zheng, X. N. Gu, and F. Witte, Mater. Sci. Eng., R77, 1 (2014).

3. J. Cheng, T. Huang, and Y. F. Zheng, J. Biomed. Mater. Res. A, 102A, 2277 (2014)

4. W. Chao, Q. Hong, H. Xiao-ying, R. Ying-mao, T. Yi, C. Yan, X. Xin-lin, X. Liang, T. Yue, and G. Run-lin, Chin. Med. J., 126, 4752 (2013)

5. X. Cui, X. Huang, Y. He, L. Dai, S. Wang, Y. Sun, W. Shi, and D. Ge, Synthetic Met., 195, 97 (2014).

6. A. Francis, Y. Yuyun, S. Virtanen, and A. R. Boccaccini, J. Mater. Sci.-Mater. M., 26, 138 (2015)

7. F. Singer, D. Ruckle, M. S. Killian, M. C. Turhan, and S. Virtanen, Int. J. Electrochem. Sci., 8, 11924 (2013).

8. L. Wang, X. Li, and Y. Yang, React. Funct. Polym., 47, 125 (2001).

9. T. V. Vernitskaya and O. N. Efimov, Russ. Chem. Rev., 66, 443 (1997).

10. S. Sadki, P. Schottland, N. Brodie, and G. Sabouraud, Chem. Soc. Rev, 29, 283 (2000).

11. P. M. George, A. W. Lyckman, and D. A. LaVan, Biomaterials, 26, 3511 (2005).

12. S. Sirivisoot, R. Pareta, and T. J. Webster, Nanotechnology, 22, 085101 (2011).

13. A. Talaie, Iran. Polym. J., 4, 26 (1995).

14. V. Misoska, J. Ding, J. M. Davey, W. E. Price, S. F. Ralph, and G. G. Wallace, Polymer, 42, 8571 (2001).

15. J. M. Davey, S. F. Ralph, C. O. Too, G. G. Wallace, and A. C. Partridge, React. Funct. Polym., 49, 87 (2001).

16. G. Shi, M. Rouabhia, Z. Wang, L. H. Dao, and Z. Zhang, Biomaterials, 25, 2477 (2004).

17. J. Mostany and B. R. Scharifker, Synthetic Met., 87, 179 (1997).

18. C. A. Ferreira, S. Aeiyach, M. Delamar, and P. C. Lacaze, J. Electroanal. Chem., 284, 351 (1990).

19. J. O. Iroh and W. Su, J. Appl. Polym. Sci., 71, 2075 (1999).

20. Y. C. Liu, B. J. Hwang, W. J. Jian, and R. Santhanam, Thin Solid Films, 374, 85 (2000).

21. V. Pillay, T. S. Tsai, Y. E. Choonara, L. C. du Toit, P. Kumar, G. Modi, D. Naidoo, L. K. Tomar, C. Tyagi, and V. M. K. Ndesendo, J. Biomed. Mater. Res. A, 102A, 2039 (2014).

22. J. I. Martins, M. Bazzaoui, T. C. Reis, E. A. Bazzaoui, and L. Martins, Synthetic Met., 129, 221 (2002) 
23. J. Prejza, I. Lundström, and T. Skotheim, J. Electrochem. Soc.: Electrochemical Science and Technology, 129, 1685 (1982).

24. H. Sung, T. Lee, and W. Paik, Synthetic Met., 69, 485 (1995).

25. A. C. Cascalheira, S. Aeiyach, P. C. Lacaze, and L. M. Abrantes, Electrochim. Acta, 48, 2523 (2003).

26. M. Bazzaoui, J. I. Martins, S. C. Costa, E. A. Bazzaoui, T. C. Reis, and L. Martins, Electrochim. Acta, 51, 4516 (2006).

27. E. Lankinen, G. Sundholm, P. Talonen, T. Laitinen, and T. Saario, J. Electroanal. Chem., 447, 135 (1998).

28. Y. Li and R. Qian, Electrochim. Acta, 45, 1727 (2000).

29. I. Rodriguez, B. R. Scharifker, and J. Mostany, J. Electroanal. Chem., 491, 117 (2000).

30. M. Bazzaoui, L. Martins, E. A. Bazzaoui, and J. I. Martins, Electrochim. Acta, 47, 2953 (2002).

31. J. Petitjean, S. Aeiyach, J. C. Lacroix, and P. C. Lacaze, J. Electroanal. Chem., 478, 92 (1999).

32. M. Bazzaoui, J. I. Martins, T. C. Reis, E. A. Bazzaoui, M. C. Nunes, and L. Martins, Thin Solid Films, 485, 155 (2005).
33. X. Du and Z. Wang, Electrochim. Acta, 48, 1713 (2003).

34. W. Xue, X. Jiang, and Y. Harima, Anal. Chem., 81, 2364 (2009).

35. M. Łapkowski and A. Proń, Synthetic Met., 110, 79 (2000).

36. K. Cysewska, J. Karczewski, and P. Jasiński, Electrochim. Acta, 176, 156 (2015).

37. R. A. Green, F. Devillaine, C. Dodds, P. Matteucci, S. Chen, P. Byrnes-Preston, L. A. Poole-Warren, N. H. Lovell, and G. J. Suaning, IEEE Eng. Med. Biol. Soc. Ann., 2010, 6769 (2010).

38. K. Włodarczyk, F. Singer, P. Jasiński, and S. Virtanen, Int. J. Electrochem. Sci., 9, 7997 (2014).

39. J. Kankare and E. L. Kupila, J. Electroanal. Chem., 322, 167 (1992).

40. M. Gholamian, T. N. Suresh Kumar, and A. Q. Contractor, Proc. Indian Acad. Sci. (Chem. Sci), 97, 457 (1986).

41. R. W. Revie and H. H. Uhlig, Corrosion and Corrosion Control: An Introduction to Corrosion Science and Engineering, p. 45, John Wiley \& Sons, Inc., New York (2008).

42. M. Lien and W. H. Smyrl, J. Electroanal. Chem., 309, 333 (1991).

43. E. Csahók, E. Vieil, and G. Inzelt, J. Electroanal. Chem., 482, 168 (2000). 